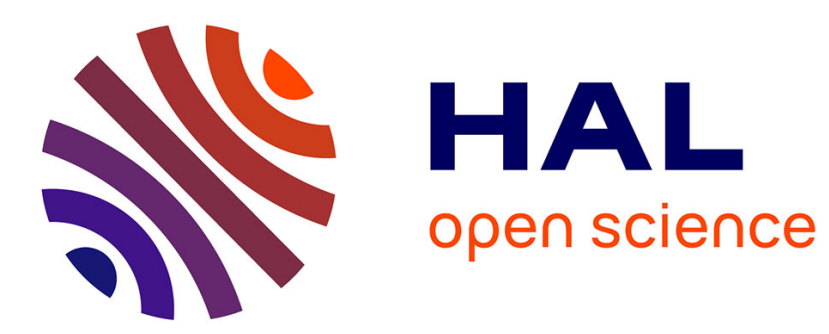

\title{
Artificial regeneration with Quercus ilex L. and Quercus suber L. by direct seeding and planting in southern Spain
} González-Rodríguez, Rafael Navarro-Cerrillo, Villar

\section{- To cite this version:}

González-Rodríguez, Rafael Navarro-Cerrillo, Villar. Artificial regeneration with Quercus ilex L. and Quercus suber L. by direct seeding and planting in southern Spain. Annals of Forest Science, 2011, 68 (3), pp.637-646. 10.1007/s13595-011-0057-3 . hal-00930792

\section{HAL Id: hal-00930792 https://hal.science/hal-00930792}

Submitted on 1 Jan 2011

HAL is a multi-disciplinary open access archive for the deposit and dissemination of scientific research documents, whether they are published or not. The documents may come from teaching and research institutions in France or abroad, or from public or private research centers.
L'archive ouverte pluridisciplinaire HAL, est destinée au dépôt et à la diffusion de documents scientifiques de niveau recherche, publiés ou non, émanant des établissements d'enseignement et de recherche français ou étrangers, des laboratoires publics ou privés. 


\title{
Artificial regeneration with Quercus ilex L. and Quercus suber $L$. by direct seeding and planting in southern Spain
}

\author{
Victoria González-Rodríguez • \\ Rafael M. Navarro-Cerrillo • Rafael Villar
}

Received: 6 March 2010 / Accepted: 14 October 2010 / Published online: 20 April 2011

(C) INRA and Springer Science+Business Media B.V. 2011

\begin{abstract}
- Introduction The limited ability of Quercus species to regenerate naturally in Mediterranean forests has led to the development of various artificial regeneration methods; however, there is no general consensus as to what specific method is the best one for this purpose.

- Material and methods In this work, we assessed morphology, growth and survival of two Quercus species (Quercus ilex ssp. ballota and Quercus suber) using two different methods of artificial regeneration (viz. direct seeding and planting) and two seedling ages (1-year-old seedlings and 3-year-old seedlings) in southern Spain.

- Results and discussion The 1-year-old seedlings of both species were found to exhibit the highest survival percentages and direct-seeded plants intermediate survival values. For direct-seeded plants, seed mass was found to have a significantly positive effect on the establishment success in both species. No clear-cut trend in survival was detected in the 3year-old seedlings. The survival of the 3-year-old $Q$. suber seedlings and the direct-seeded plants was similar, but not in Q. ilex, where the survival of the 3-year-old seedlings was the
\end{abstract}

\section{Handling Editor: Douglass Jacobs}

Electronic supplementary material The online version of this article (doi:10.1007/s13595-011-0057-3) contains supplementary material, which is available to authorized users.

V. González-Rodríguez $\cdot$ R. Villar $(\bowtie)$

Área de Ecología, Edificio Celestino Mutis,

Campus de Rabanales, Universidad de Córdoba,

14071 Córdoba, Spain

e-mail: bv1vimor@uco.es

R. M. Navarro-Cerrillo

Departamento de Ingeniería Forestal, Edificio Leonardo da Vinci,

Campus de Rabanales, Universidad de Córdoba,

14071 Córdoba, Spain lowest. The latter result may have been a consequence of cultivation in smaller containers leading to root deformation and limiting plant access to water. Differences in survival could not be ascribed to morphological and growth variables or stomatal conductance.

- Conclusion Based on the results, all three artificial regeneration methods can be similarly effective provided appropriate nursery cultivation conditions are used and seeds are protected against predators, the best choice in each case being dictated by the particular restoration goals.

Keywords Artificial regeneration · Nursery · Oak · Seedling age $\cdot$ Sowing

\section{Introduction}

Holm oak [Quercus ilex L. ssp. ballota (Desf.)] and cork oak (Quercus suber L.) are two evergreen woody species widely represented in the wild and managed forests of the Iberian Peninsula. Also, they constitute two essential elements of the agro-sylvopastoral system known as "dehesa". Ensuring sustainable use of natural resources in savanna-like ecosystems (dehesas) is of great economic importance for rural areas.

Oak tree mortality has increased considerably over the past 20 years due to the effect of the combined action of pathogens, xylophagous insects and adverse climate conditions (Brasier 1996). Poor regeneration (Smit et al. 2009) and high adult mortality (Brasier 1996) in many areas have led to the implementation of artificial regeneration programmes, mainly in areas where the tree population has declined or disappeared, or the land has been converted to agriculture.

Artificial regeneration with Quercus trees is limited by many factors including acorn predation, slow growth, and 
low survival percentages especially during the first summer drought (Smit et al. 2009). In addition, Quercus seeds are recalcitrant, so they can only be stored for a few months.

No consensus exists as to which is the best available artificial regeneration method for Quercus. The greatest advantage of direct seeding is probably its low cost relative to planting as the latter requires nursery care and planting with higher associated costs (Stanturf et al. 1998). Moreover, direct-seeded plants can develop natural root systems on site and longer roots reaching deeper soil layers so that they have access to water more readily during the first summer drought, thus increasing survival (Lloret et al. 1999).

However, direct-seeded plants remain in a more vulnerable condition over longer periods (Stanturf et al. 1998) and they also grow to a lesser extent (Zaczek et al. 1996). The one other disadvantage of acorns is vulnerability to predation by wild animals (Johnson et al. 2002), especially in small openings or forested areas over the first few weeks after sowing (Madsen and Löf 2005).

Nursery production of oak seedlings is believed to be a more reliable regeneration method than direct seeding, this being especially recommended when seed supply is limited (King and Keeland 1999). Thus, it considerably reduces initial predation, and results in increased growth and more efficient competition with grasses (Stanturf and Kennedy 1996). With respect to seedling age, Spanish legislation has set various quality conditions for nursery seedlings including a maximum seedling age of 1-2 years for $Q$. ilex and 1 year for $Q$. suber. However, those standards should be considered as reference values, and it has been shown in several studies (e.g. Navarro-Cerrillo et al. 2007; Jacobs et al. 2009). On the other hand, the growing use of plants to increase density and enrich existing dehesas has led nurseries to grow older $Q$. ilex and $Q$. suber seedlings (3-4 years) in larger containers $\left(1,000-3,000 \mathrm{~cm}^{3}\right)$. This has allowed the initial growth period in the field to be shortened, thus obtaining more visible results within a shorter time after planting. However, planting larger seedlings is more expensive than planting small ones (Stanturf et al. 2004).

Which attributes explain seedling performance in the field? Various morphological traits including aerial biomass, height and the root/shoot biomass ratio dictate growth and survival (Navarro-Cerrillo et al. 2007) and have frequently been used to predict seedling performance in the field (Davis and Jacobs 2005; Jacobs et al. 2005). There is, however, no general agreement about the most suitable plant morphology for the Mediterranean environment. Some studies (Del Campo et al. 2010; VillarSalvador et al. 2004) have found no relationship between plant performance and seedling morphology; also, the plant's early response is believed to be more markedly dependent on the particular local conditions (Dey et al. 2008; Palacios et al. 2009). One of the main causes of failure in reforestation actions is summer drought. Water stress affects planting stock and seedling establishment (Grossnickle 1988) and can be reflected in stomatal conductance changes (Stewart and Bernier 1995). In fact, stomatal conductance reflects the water use strategy of plants; thus, stomatal closure avoids excessive transpiration and xylem cavitation (Cochard et al. 1996), but can compromise photosynthesis and reduce the growth potential of plants as a result.

In short, the choice of a particular artificial regeneration method is dictated by a number of factors including site conditions, seedling quality and water status, the particular species to be regenerated and the specific objectives of the restoration project (Dey et al. 2008). Identifying the best possible artificial regeneration method in each case usually entails assessing them under different conditions and examining the morphological and physiological processes that underlie seedling outplanting performance. No previous simultaneous assessment of direct seeding and planting of 1- and 3-year-old seedling with $Q$. ilex and $Q$. suber oaks has, to the authors' knowledge, been done. The primary purposes of this study were, therefore, as follows: (a) to compare seedling performance of plants using three methods: direct seeding and planting of 1- and 3-year-old seedlings of the two most common oak species in the Iberian Peninsula; (b) to confirm whether morphological or physiological attributes can be used to explain seedling performance in the field; and (c) to identify the most suitable artificial regeneration method for these two species.

\section{Material and methods}

\subsection{Site description}

The study was carried out in an experimental plot at the University of Córdoba (Campus de Rabanales, Córdoba, Spain, $37^{\circ} 51^{\prime} \mathrm{N}, 4^{\circ} 48^{\prime} \mathrm{W}, 100 \mathrm{~m}$ a.s.l.) that was formerly used as agricultural land. The site has a small slope $(<2 \%)$ and the soil is a fluvisol consisting of heterometric silical gravels containing occasional calcareous boulders. Physical and chemical soil characteristics are shown in Appendix S1. The climate is dry Mediterranean, with a mean annual temperature of $17.6^{\circ} \mathrm{C}$, an average rainfall of $609 \mathrm{~mm}$ and dry summers. The average temperature and atmospheric humidity for the period from April to October 2008 were recorded with a data logger (HOBO Pro Series 8 Temp, RH) located in the area. The average temperature during the first 8 months (February-September 2008) was $23.9 \pm 5.1^{\circ} \mathrm{C}$ and the accumulated precipitation was $604 \mathrm{~mm}$ (Appendix S2). 


\subsection{Seed collection and seedling assessment}

From October to December 2007, approximately 800 acorns of $Q$. ilex L. subsp. ballota (Desf.) Samp. and $Q$. suber L. with no apparent damage were collected from the Natural Park of Sierra de Cardeña and Montoro (Sierra Morena, Córdoba, Spain, $38^{\circ} 21^{\prime} \mathrm{N}, 3^{\circ} 12^{\prime} \mathrm{W}$; for $Q$. ilex, the provenance region was Extremadurense, and for $Q$. suber, the provenance region was Sierra Morena Oriental; Jiménez et al. 1996; Martín-Albertos et al. 1998). Seeds were obtained from at least six trees in the same population. Acorns were stored at $2-5^{\circ} \mathrm{C}$ in a cold chamber until January 2008. The acorns to be used for direct seeding were selected by the flotation method. A sub-sample of each species was used to determine fresh weight and then oven-dried at $70^{\circ} \mathrm{C}$ for at least $48 \mathrm{~h}$. Seed dry mass was determined after removing the pericarp from the cotyledons. Linear regression equations between acorn fresh mass $\left(A_{\mathrm{FM}}\right)$ and seed dry mass $\left(S_{\mathrm{DM}}\right)$ were established for each species in order to obtain a precise enough estimate of seed dry mass from acorn fresh mass. The equation for $Q$. ilex was $S_{D M}=-0.2878+0.5412 \times A_{F M}$ $\left(r^{2}=0.95, P<0.001\right)$, and for $Q$. suber, the equation was $S_{D M}=-0.1167+0.6019 \times A_{F M}\left(r^{2}=0.98, P<0.001\right)$.

In January 2008, several sets of $Q$. ilex and $Q$. suber seedlings cultivated in a forest nursery were selected (San Jerónimo, Consejería de Medio Ambiente, Junta de Andalucía, Seville, Spain). For Q. ilex, the provenance region was Extremadurense, and for $Q$. suber, the provenance region was Sierra Morena Occidental (Jiménez et al. 1996; Martín-Albertos et al. 1998). The 1-year-old seedlings of $Q$. ilex (height, $13.8 \pm 2.2 \mathrm{~cm}$; stem basal diameter, $0.35 \pm 0.07 \mathrm{~cm}$ ) and Q. suber (height, $34.7 \pm 9.7 \mathrm{~cm}$; stem basal diameter, $0.36 \pm 0.07 \mathrm{~cm}$ ) were grown in $400 \mathrm{~cm}^{3}$ Forestpot $^{\circledR}$ containers. The 3-year-old seedlings of $Q$. ilex (height, $61 \pm 12.4 \mathrm{~cm}$; stem basal diameter, $1.31 \pm 0.29 \mathrm{~cm}$ ) were grown in Forestpot ${ }^{\circledR} 3,000 \mathrm{~cm}^{3}$ containers and $Q$. suber seedlings of the same age (no measurements available) cultivated in $7,200 \mathrm{~cm}^{3}$ individual pots. A randomly selected sample of 15-20 seedlings of each species and age was harvested (first harvest planting) before planting for the measurement of root, stem, and leaf dry biomass after oven-drying at $70^{\circ} \mathrm{C}$ for at least 2 days. All leaves were scanned (HP Scan-jet 6300c) for calculation of total leaf area with the image analysis software Image Pro-plus 4 (Media Cybernetics, Inc.). Specific leaf area (SLA) was calculated as the ratio of leaf area to leaf dry mass. Biomass allocation to leaves (LMF, leaf mass fraction), stems (stem mass fraction), and roots (root mass fraction) was calculated as the ratio of organ biomass to total biomass. Roots were manually classified as fine (less than 1-mm thick) or coarse (more than 1-mm thick).

\subsection{Experimental design}

The plot studied was tilled to a depth of $40 \mathrm{~cm}$ with an agricultural harrow and the soil removed with a single shank ripper. The experiment was arranged as a factorial design involving two species $(Q$. ilex and $Q$. suber $)$ and three age levels (seeds, 1-year-old seedlings and 3-year-old seedlings) in a completely randomized three-block design. Hereafter, the three age levels will be designated as "artificial regeneration methods". Seeds were sown and seedlings planted in $2 \times 2 \mathrm{~m}$ spacing in each block. For direct seeding, 150 acorns of each species were distributed in each block. Three seeds per point were sown, at a depth of $5 \mathrm{~cm}$, to ensure emergence. Seeds were placed $10 \mathrm{~cm}$ apart. The fresh mass of each acorn was recorded before seeding. In addition, 50 1-year-old seedlings and 50 3-year-old seedlings of each species were planted in each block. Therefore, a total of 750 samples from each species were used. Both direct seeding and planting were performed in late January 2008. Weed control during the experiment was done by manual removal and motorized cultivator during the spring.

\subsection{Survival assessment}

Acorn emergence and seedling survival were assessed at 15day intervals from February to September 2008, and once more in September 2009. Two survival percentages were calculated, one for plants surviving after the first summer (September 2008) and the other for those still alive after the second (September 2009). Two performance-related variables (survival and success) were determined for directly seeded samples. Survival was calculated as the proportion of plants remaining alive after summer relative to emerged plants, and success as the number of plants surviving the summer divided by the total number of acorns sown. Therefore, the success was a combination of emergence and survival. We also estimated plot success as the proportion of planting spots with at least one plant established relative to planting spots.

\subsection{Morphological measurements}

In April 2008, a sub-sample of 15 seedlings from directly sown seeds of each species was randomly selected from the three blocks for removal of their aerial fraction (first harvest seeding) and measurement of the dry mass of each part, leaf area and SLA as described above.

At the end of September of 2008, a sub-sample of 15 seedlings from each factorial treatment was randomly selected from the three blocks. Whole seedlings were removed from the soil, and their roots washed and cleaned (second harvest). The mean root depth was $28.4 \pm 4.9 \mathrm{~cm}$. Total biomass was split into leaves, stems and roots, and morphological variables were calculated by following the 
above-described procedure. Absolute shoot and root mean increments were calculated as the mean differences between shoot or root dry mass of each method at the second and first harvest. Shoot and root mean increments for seedlings from directly sown seeds were taken to be the shoot or root dry mass values obtained at the second harvest as no shoots or roots existed at seeding time. The relative growth rate (RGR) for each method was calculated from the following expression (Hoffmann and Poorter 2002):

$R G R=\left[\ln \left(M_{2}\right)-\ln \left(M_{1}\right)\right] /\left(t_{2}-t_{1}\right)$

where $\ln \left(M_{2}\right)$ and $\ln \left(M_{1}\right)$ denote the mean ln-transformed plant dry mass at time $t_{1}$ and $t_{2}$, respectively. $M_{2}$ and $t_{2}$ corresponded to the second harvest for all artificial regeneration methods, whereas $M_{1}$ and $t_{1}$ differed between methods. For 1- and 3-year-old cultivated seedlings, $M_{1}$ and $t_{1}$ corresponded to the first harvest before planting; for seedlings from directly sown seeds, $M_{1}$ and $t_{1}$ corresponded to the first seeding harvest (after emergence of seedlings). The standard deviation for RGR was calculated according to Cornelissen et al. (1996).

\subsection{Physiological measurements}

Two types of measurements were done: stomatal conductance and leaf water content. A porometer (delta T porometer AP4) was used to measure leaf stomatal conductance. Measurements were made every 2 weeks at midday (10-12 a.m. solar time) on four randomly selected replicates per species during the dry season (June to August 2008). Measurements were made on completely expanded young leaves receiving full sunlight.

From May to October 2008, ten seedlings per method were selected monthly for measurement of leaf water content. A young leaf directly hit by sunlight was collected from each replicate. Leaves were rapidly transferred to individual plastic pots that were previously weighed and covered with parafilm. Samples were brought back to the laboratory for weighing (within $1 \mathrm{~h}$ of collection) and then oven-dried at $70^{\circ} \mathrm{C}$ for at least $48 \mathrm{~h}$ to measure dry mass. Leaf water content was calculated as $W C=$ $(F W-D W) \times 100 / F W$, where $\mathrm{FW}$ and $\mathrm{DW}$ are fresh and dry weight, respectively.

\subsection{Data analyses}

Differences in seedling survival for each species between methods were assessed by using log-rank survival curves constructed by following the Kaplan-Meier procedure (Kaplan and Meier 1958). This analysis considers both seedling longevity and status (dead or alive) at the last survival assessment. In each species, differences in morphological and physiological attributes were analysed by one-way ANOVA with method as factor and a post hoc Tukey test. When necessary, data were converted into logarithmic form in order to fulfill normality and variance homogeneity requirements. A non-parametric Kruskal-Wallis test was applied in those cases where the transformed data failed to fulfill the ANOVA assumptions. The potential effect of blocks was excluded from the statistical analysis since they introduced no changes in survival trends. All statistical analyses were done with the software STATISTICA 8.0. (Statsoft, Inc.).

\section{Results}

\subsection{Survival}

Eight months after planting, 1-year-old $Q$. suber seedlings exhibited the highest survival percentages ( $c a .68 \%$ ), and 3year-old $Q$. ilex seedlings, the lowest (ca. 25\%; Table 1). Twenty months after planting, all seedlings exhibited lower survival than after 8 months, but both survival percentages

Table 1 Survival, seedling success and plot success for the first and second year in the two Quercus species studied using the three artificial regeneration methods

\begin{tabular}{|c|c|c|c|c|c|c|c|}
\hline & & \multicolumn{2}{|c|}{ Survival (\%) } & \multicolumn{2}{|c|}{ Seedling success $(\%)$} & \multicolumn{2}{|c|}{ Plot success (\%) } \\
\hline & & First year & Second year & First year & Second year & First year & Second year \\
\hline \multirow[t]{3}{*}{ Q. ilex } & ds & $51.5 \pm 14.7$ & $34.96 \pm 9.2$ & \multirow[t]{3}{*}{$17.2 \pm 9.9$} & \multirow[t]{3}{*}{$11.7 \pm 7.2$} & \multirow[t]{3}{*}{$42.66 \pm 18.03$} & \multirow[t]{3}{*}{$24.66 \pm 11.01$} \\
\hline & $1 \mathrm{ys}$ & $61.1 \pm 19.8$ & $45.28 \pm 19.3$ & & & & \\
\hline & $3 y s$ & $24.9 \pm 18.7$ & $17.74 \pm 10.3$ & & & & \\
\hline \multirow[t]{3}{*}{ Q. suber } & ds & $47.9 \pm 9.4$ & $33.6 \pm 2.4$ & \multirow[t]{3}{*}{$31.8 \pm 13.9$} & \multirow[t]{3}{*}{$22.3 \pm 7.4$} & \multirow[t]{3}{*}{$44.66 \pm 8.08$} & \multirow[t]{3}{*}{$32.33 \pm 8.50$} \\
\hline & $1 \mathrm{ys}$ & $67.7 \pm 14.6$ & $60.5 \pm 11.1$ & & & & \\
\hline & $3 y s$ & $45.1 \pm 13.6$ & $37.6 \pm 25.1$ & & & & \\
\hline
\end{tabular}

Seedling success (percentage of seedlings established from the acorns sown) and plot success (percentage of planting spots with at least one plant established). First year and second year were 8 and 20 months after being planted (after first and second dry season). Mean value and standard deviation of the three blocks' percentages are shown. The three artificial regeneration methods are: $d s$ direct-seeded, $1 y s$ 1-year-old seedling, and 3ys 3-year-old seedling 

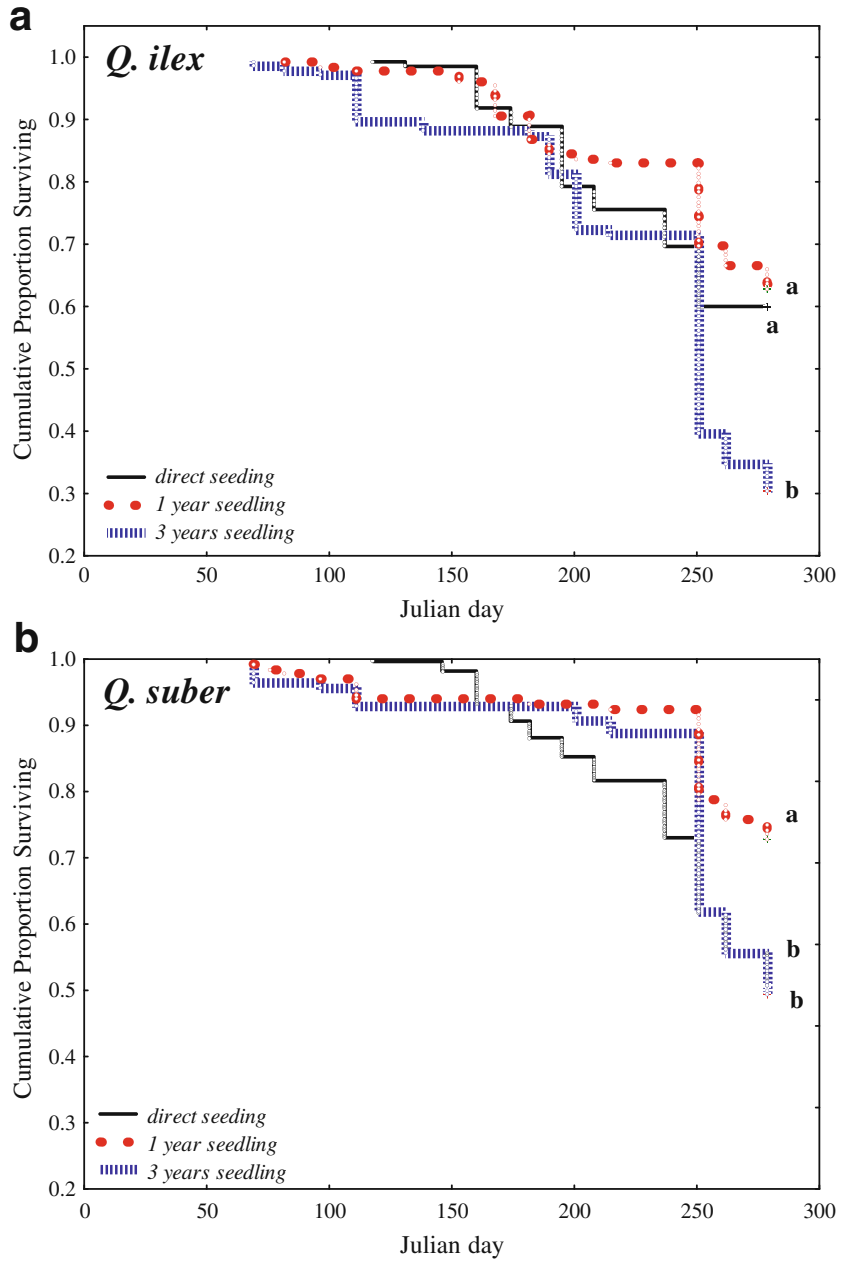

Fig. 1 Percent survival of $Q$. ilex (a) and $Q$. suber (b) seedlings during the first dry season. Different letters represent statistically different groups according to Kaplan-Meier survival analysis (logrank tests; $P<0.05$ )

showed a high correlation coefficient $(r=0.95, P=0.003$ ). Therefore, survival patterns were similar in both periods, thus meaning that methods with the highest survival after 8 months also had the highest survival after 20 months. At species level, log-rank tests revealed significantly lower survival of 3-year-old $Q$. ilex seedlings relative to the other methods (Fig. 1a). Also, 1-year-old $Q$. suber seedlings exhibited significantly higher survival percentages than 3year-old seedlings of the same species and directly seeded plants (Fig. 1b).

Seedling success (a combination of emergence and survival) for the first year in directly seeded plants was about $17 \%$ for $Q$. ilex and $32 \%$ for $Q$. suber, and plot success (percentage of planting spots with at least one plant established) was about $43 \%$ for $Q$. ilex and $45 \%$ for $Q$. suber for the first year (Table 1). The second year seedling success decreased to $12 \%$ in Q. ilex and to $22 \%$ in $Q$. suber (Table 1; about a $30 \%$ decrease with respect to the first year).
Plot success also decreased the second year for both species (Table 1).

Seedling success was significantly affected by seed mass $(F=14.3, P<0.001)$. In both species, successful seedlings had larger acorns than the unsuccessful ones, the effect being significant for $Q$. ilex (Fig. 2). Because seedling success was a combination of emergence and survival, the seed mass may have influenced either variable. Interestingly, the favourable effect of seed mass was felt on survival in Q. ilex $(F=9.24, P=0.002)$ but on emergence in $Q$. suber $(F=10.66, P=0.001)$.

\subsection{Seedling growth and morphology}

Morphological attributes differed with seedling age, both on the planting date (Appendix S3) and 8 months later (Table 2). The change in root biomass was generally lower in the older seedlings, and so were the RGR, SLA and LMF for both species (Table 2). The root/shoot ratio of the older seedlings was higher except for the 3-year-old $Q$. suber seedlings, which exhibited the lowest ratios. The 1-year-old $Q$. suber seedlings had the highest fine roots proportion $(16.7 \pm 4.3 \%)$ both at the first harvest (i.e. planting time; Appendix S3) and at the second harvest (Table 2).

\subsection{Ecophysiological measurements}

Figure 3 shows the stomatal conductance evolution for the dry period (June to August 2008). The 3-year-old seedlings of both species had lower mean conductance values than both 1-year-old seedlings and the plants from directly sown seeds throughout the dry season (Fig. 3). The mean maximum conductance at the start of the dry period ranged from $90 \pm 67 \mathrm{mmol} \mathrm{m}^{-2} \mathrm{~s}^{-1}$ for 3-year-old $Q$. ilex seedlings

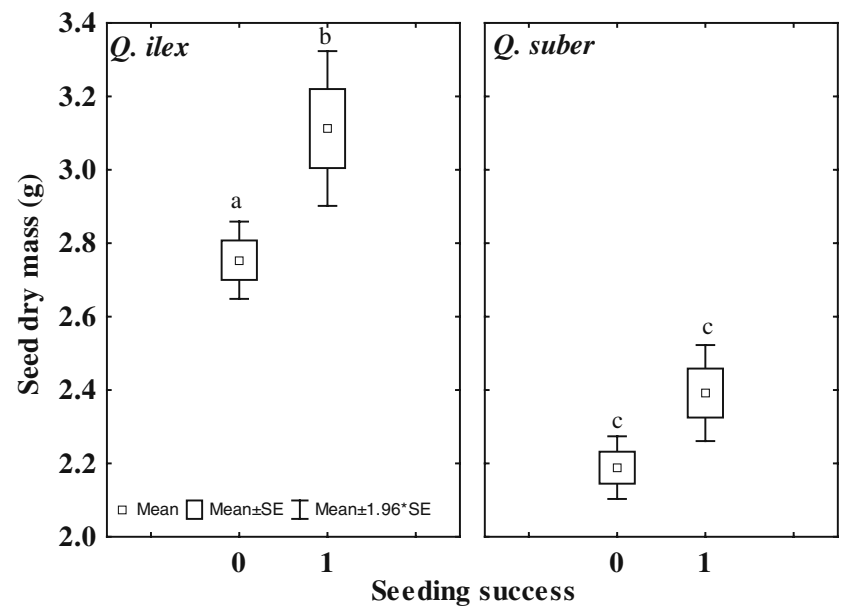

Fig. 2 Differences in initial seed dry mass between emerged and live seedlings (1) and non-emerged or dead seedlings after 8 months. Different letters represent statistically different groups according to the post hoc Tukey test $(P<0.05)$ 
Table 2 Summary of the biomass allocation and growth variables (mean $\pm \mathrm{SD})$ in $Q$. ilex and $Q$. suber at the end of the first dry season

\begin{tabular}{|c|c|c|c|c|c|c|}
\hline & \multicolumn{3}{|l|}{ Q. ilex } & \multicolumn{3}{|l|}{ Q. suber } \\
\hline & ds & $1 \mathrm{ys}$ & 3ys & ds & $1 \mathrm{ys}$ & 3ys \\
\hline Root biomass (g) & $0.72 \pm 0.45$ & $3.97 \pm 1.50$ & $39.42 \pm 10.20$ & $0.83 \pm 0.43$ & $6.73 \pm 3.86$ & $47.13 \pm 11.39$ \\
\hline Stem biomass (g) & $0.61 \pm 0.28$ & $2.30 \pm 1.05$ & $25.15 \pm 15.82$ & $0.51 \pm 0.32$ & $4.03 \pm 2.17$ & $60.48 \pm 14.88$ \\
\hline Leaf biomass (g) & $0.60 \pm 0.33$ & $2.07 \pm 0.59$ & $9.26 \pm 6.58$ & $0.40 \pm 0.21$ & $1.79 \pm 0.95$ & $16.15 \pm 5.40$ \\
\hline Total biomass (g) & $1.80 \pm 0.87$ & $8.15 \pm 2.46$ & $76.04 \pm 31.38$ & $1.82 \pm 0.72$ & $12.64 \pm 5.51$ & $124.26 \pm 25.16$ \\
\hline$\Delta$ root biomass $*(\mathrm{~g})$ & $0.72 \pm 0.45$ & $-0.43 \pm 1.49$ & $-1.64 \pm 10.20$ & $0.83 \pm 0.43$ & $0.53 \pm 3.86$ & n.a. \\
\hline$\Delta$ shoot biomass $*(\mathrm{~g})$ & $1.21 \pm 0.57$ & $1.84 \pm 1.44$ & $8.56 \pm 19.46$ & $0.91 \pm 0.46$ & $1.64 \pm 2.52$ & n.a. \\
\hline RGR (mg g ${ }^{-1}$ day $^{-1}$ ) & $4.1 \pm 1.35$ & $2.2 \pm 0.88$ & $1.2 \pm 6.02$ & $4.9 \pm 2.45$ & $1.3 \pm 3.52$ & n.a. \\
\hline SLA $\left(\mathrm{m}^{2} \mathrm{~kg}^{-1}\right)$ & $9.70 \pm 5.22 \mathrm{a}$ & $7.53 \pm 3.92 \mathrm{a}$ & $4.53 \pm 0.30 \mathrm{~b}$ & $12.73 \pm 6.97 \mathrm{~A}$ & $12.82 \pm 7.70 \mathrm{~A}$ & $10.79 \pm 6.18 \mathrm{~A}$ \\
\hline $\operatorname{LMF}\left(\mathrm{kg} \mathrm{kg}^{-1}\right)$ & $0.30 \pm 0.10 \mathrm{a}$ & $0.25 \pm 0.04 \mathrm{a}$ & $0.11 \pm 0.05 \mathrm{~b}$ & $0.21 \pm 0.05 \mathrm{~A}$ & $0.15 \pm 0.04 \mathrm{~B}$ & $0.13 \pm 0.04 \mathrm{~B}$ \\
\hline SMF $\left(\mathrm{kg} \mathrm{kg}^{-1}\right)$ & $0.33 \pm 0.07 \mathrm{a}$ & $0.26 \pm 0.05 \mathrm{a}$ & $0.34 \pm 0.10 \mathrm{a}$ & $0.32 \pm 0.15 \mathrm{~A}$ & $0.32 \pm 0.20 \mathrm{~A}$ & $0.49 \pm 0.06 \mathrm{~A}$ \\
\hline $\operatorname{RMF}\left(\mathrm{kg} \mathrm{kg}^{-1}\right)$ & $0.38 \pm 0.12 \mathrm{~b}$ & $0.48 \pm 0.08 \mathrm{a}, \mathrm{b}$ & $0.55 \pm 0.11 \mathrm{a}$ & $0.47 \pm 0.16 \mathrm{~A}$ & $0.54 \pm 0.18 \mathrm{~A}$ & $0.38 \pm 0.06 \mathrm{~A}$ \\
\hline Fine roots $(\%)$ & $9.02 \pm 12.47 \mathrm{a}$ & $9.18 \pm 6.07 \mathrm{a}$ & $15.44 \pm 5.24 \mathrm{a}$ & $2.77 \pm 4.42 \mathrm{~B}$ & $17.12 \pm 15.78 \mathrm{~A}$ & $4.96 \pm 3.41 \mathrm{~B}$ \\
\hline Root/shoot & $0.66 \pm 0.32 \mathrm{~b}$ & $0.96 \pm 0.28 \mathrm{a}, \mathrm{b}$ & $1.38 \pm 0.70 \mathrm{a}$ & $0.90 \pm 0.50 \mathrm{~A}, \mathrm{~B}$ & $1.40 \pm 0.71 \mathrm{~A}$ & $0.63 \pm 0.18 \mathrm{~B}$ \\
\hline
\end{tabular}

Values of root, stem and leaf biomass, specific leaf area (SLA), leaf mass fraction (LMF), stem mass fraction (SMF), root mass fraction (RMF), root/shoot and percentage of fine roots are from plants in second harvest (after 8 months of being planted). Shoot and root mean increments were calculated as the mean differences between shoot or root dry mass of each afforesation method at the second and first harvest. At each species, different letters in rows (lower case letters for $Q$. ilex and capital letters for $Q$. suber) represent statistically different groups according to post hoc Tukey test $(P<0.05)$ or to Kruskal-Wallis test when data did not fulfill ANOVA assumptions $(Q$. ilex SLA and $Q$. suber SMF). Fine roots percentage data were square root transformed in order to fulfill ANOVA requirements

$d s$ direct-seeded, 1ys 1-year-old seedling, 3ys 3-year-old seedling, n.a. not available

* Shoot and root mean increments were calculated as the mean differences between shoot or root dry mass of each afforesation method at the second and first harvest

to $226 \pm 95 \mathrm{mmol} \mathrm{m}^{-2} \mathrm{~s}^{-1}$ for direct-seeded $Q$. suber plants (Fig. 3). Conductance decreased considerably throughout the dry season in all plant types. At the end of the dry period, 3-year-old $Q$. suber seedlings exhibited the lowest conductance values $\left(6 \pm 0.5 \mathrm{mmol} \mathrm{m} \mathrm{m}^{-2} \mathrm{~s}^{-1}\right)$ and 1-year-old Q. suber seedlings, the highest $\left(90 \pm 29 \mathrm{mmol} \mathrm{m}^{-2} \mathrm{~s}^{-1}\right)$, the differences being significant - the conductance of 3-yearold $Q$. suber seedlings was significantly lower than those for the other treatments $(F=10.97, P=0.003)$. There were also substantial differences between individual specimens of the same species (Fig. 3).

Leaf water content varied little with time (results not shown). The mean water content was highest for directseeded $Q$. suber plants $(56.6 \pm 9.5)$ and lowest for 3-yearold $Q$. ilex seedlings (47.6 \pm 5.7$)$; the differences, however, were not statistically significant.

\section{Discussion}

In this study, we simultaneously evaluated direct seeding and planting of 1- and 3-year-old seedlings of the two most common oak species in the Mediterranean region $(Q$. ilex and $Q$. suber). We found that 1 -year-old seedlings of both species perform much better than the other methods. In fact, this age has been recommended as being optimal for planting in Mediterranean conditions (Villar-Salvador 2003). However, the other methods (direct seeding and planting 3year-old seedlings) may offer other advantages.

Seedlings obtained by direct sowing had medium survival percentages (about 50\% the first year and 33\% the second). Mendoza et al. (2009) had found that direct seedling survival depended on the specific habitat and was lower (from 30\% to $50 \%$ ) in open sites that are comparable to our study area. However, Navarro et al. (2006) found high survival percentages $(80 \%)$ in directly sown seedlings 2 years after seeding, and proposed the seeding method as a viable choice for forest restoration.

Oak seedlings obtained by direct seeding must rely heavily on available acorn reserves. We found plants from large acorns to be more successful than those from small acorns as a result of the combined effect of emergence and survival. A relationship between seed mass and both seedling and root mass in Quercus has been established (Quero et al. 2007), based on which seeding large acorns can be expected to provide more vigorous seedlings with an increased survival likelihood (Lloret et al. 1999), especially under adverse environmental conditions, such as drought

With respect to the 3-year-old seedlings, several studies have found that large seedlings have higher survival and 
a

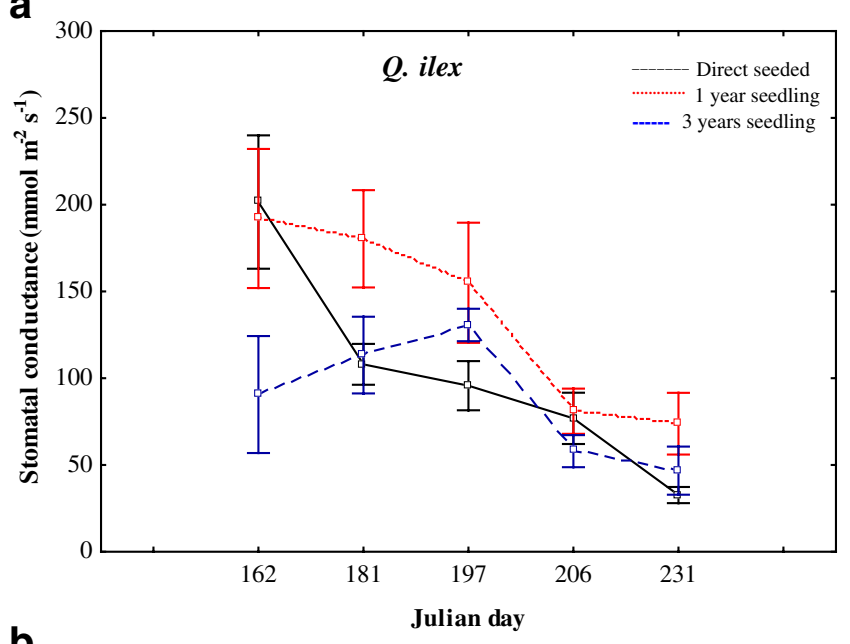

b

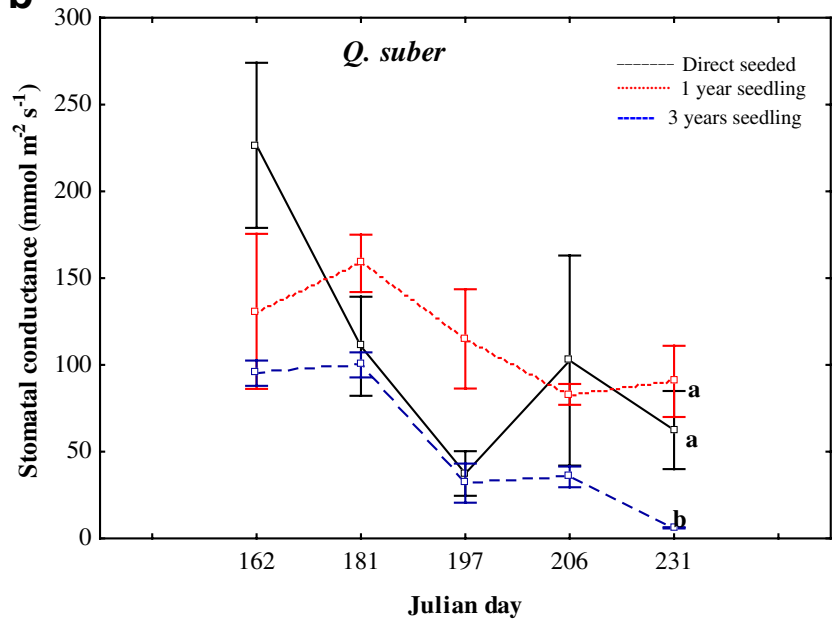

Fig. 3 Stomatal conductance of $Q$. ilex (a) and $Q$. suber (b) at midday during the dry season. Bars represent standard errors and different letters represent statistically different groups according to the post hoc Tukey test $(P<0.05)$ on a given date

growth relative to small seedlings in the Mediterranean environments (Puértolas et al. 2003; Villar-Salvador et al. 2008; Luis et al. 2009; Oliet et al. 2009). Large seedlings may have higher net carbon gain because its greater photosynthetic surface area than small seedlings (Villar-Salvador 2003), and it may stimulate root growth during the wet season and thus allow seedlings to extract water in the dry season, ensuring plant survival (Padilla and Pugnaire 2007).

However, no clear conclusion can be drawn as regards survival in 3-year-old seedlings in our study. Thus, $Q$. suber exhibited medium percentages (about $50 \%$ in the first year) that were comparable to those for direct-seeded plants, and $Q$. ilex had very low values $(25 \%)$ that departed significantly from those for the other methods. Initial seedling growth ("vigor") is a critical factor related to morphological and physiological attributes during the establishment period (Ashton et al. 1999). Older plants may exhibit abnormal root growth from the effect of their cultivation in small containers (Pemán et al. 2006) and develop inadequately after planting as a result (Dey et al. 2008), thereby being at an increased risk of dying during the first summer drought. In this study, containers that were used to grow 3-year-old Q. ilex seedlings were considerably smaller than those for 3-year-old $Q$. suber seedlings. Seedlings grown in deep containers have similar root systems to those of naturally grown plants and exhibit a greater root development capacity and hydraulic conductance than those growing in smaller containers (Pemán et al. 2006; Chirino et al. 2008). Moreover, removal of seedling roots from the soil after 8 months of growth in the field revealed that the nursery seedlings had developed few new roots outside the nursery container root volume (see values around zero in Table 2); by contrast, the roots of direct-seeded plants had grown deeper into the soil. The depth of the root system allows seedlings to access water during the dry season (Pemán et al. 2006). In this sense, Padilla and Pugnaire (2007) found a strong positive relationship between survival and maximum rooting depth in the five Mediterranean woody species. The relatively small container of 3-year-old $Q$. ilex may have been critical, determining less vigorous plants with less deep roots than the others that may partly account for their poor survival due to the effect of their strengthening container constraints on root growth.

Although seedlings with an increased root/shoot ratio can be expected to survive quite well in water deficit situations (Jacobs et al. 2009; Lloret et al. 1999), we found no lower root/shoots ratios in 3-year-old $Q$. ilex seedlings from the effect of their previous cultivation in small nursery containers or their lower survival. Similarly, previous studies in Mediterranean found no relationship between root/shoot ratio and seedling performance (Del Campo et al. 2010; Padilla and Pugnaire 2007; Villar-Salvador et al. 2004) or container size (Chirino et al. 2008). Our results are suggestive of slightly greater root mass allocation in the larger plants, but this requires confirmation by a careful study of the morphology and structure of the roots. Possibly, there was a markedly thickened main root, so the actual surface area available for water and nutrient uptake was probably small. Jacobs et al. (2009) also found that larger root volume does not confer seedlings with drought avoidance, and the most effective drought avoidance mechanisms were root growth, stomatal regulation, reduced leaf area and higher growth allocation to roots relative to shoots. On the other hand, oneyear-old $Q$. suber seedlings showed a high proportion of fine roots at planting time and must therefore have had an increased physiological capacity for water and nutrient uptake (Eissenstat 1992).

Apart from fine roots proportion, performance differences can seemingly not be explained in terms of the morphological variables studied. Previous studies, which aimed to identify morphological attributes thus allowing 
seedling field performance to be predicted, found either no definite relationships or relationships that changed with the meteorological conditions of the planting year (Del Campo et al. 2010; Palacios et al. 2009). Also, species may differ in the response depending on the phenotypic plasticity. For example, Cuesta et al. (2010) found that holm oak seedlings under different nursery conditions did not show differences in mortality after transplanting while Aleppo pine did, suggesting that the lower phenotypic plasticity of late successional species (oaks) may explain these results.

All regeneration methods exhibited similar trends in stomatal conductance with time. Physiological parameters related to water use may change with plant age and developmental stage (Cavender-Bares and Bazzaz 2000); also, differences between species may not be apparent at the seedling stage (Mediavilla and Escudero 2004). Thus, although $Q$. ilex is known to develop an extremely conservative strategy for water use, it exhibits a low stomatal sensitivity and high conductance at the seedling stage (Mediavilla and Escudero 2004). The decrease in conductance in the dry season was a response to prevent xylem cavitation through stomatal control (Vilagrosa et al. 2003). Although all plant types exhibited a similar strategy, directly seeded and 1-year-old seedlings seemingly had a better water status - reflected in increased stomatal conductance-during the dry period. The 3-year-old seedlings (especially those of $Q$. suber) exhibited a higher stomatal sensitivity, a strategy which may reduce its growth rate. Also, older seedlings had lower leaf water contents $(Q$. ilex) and SLA values, both traits being closely related to RGR (Cornelissen et al. 1996; Ruiz-Robleto and Villar 2005). In fact, SLA and RGR decreased with age, which was to be expected since younger seedlings need to develop more leaves and have higher photosynthesis rates in order to reach the growth potential they require for successful establishment. Increased SLA values are suggestive of rapid production of biomass, but are related to low values of efficient conservation of nutrients (Poorter and Garnier 1999) and water (Poorter et al. 2009). On the other hand, the more conservative strategy of the older seedlings could be successful under extremely dry or stressing conditions. Thus, under the conditions of a high evaporation demand and low water availability, large seedlings may undergo more marked reductions in growth and conductance than small seedlings (Stewart and Bernier 1995), as we indeed found here. Moreover, older oak seedlings had lower LMF values at both harvests. Finally, leaf dieback has been noted as a response to high water stress by reducing passive water losses (Vilagrosa et al. 2003) and may have been the specific strategy adopted by our 3-year-old oak seedlings.

It should be noted that the collection of seeds for seeding and for seedlings were from different populations, so it could introduce confounding effects. However, for $Q$. ilex, the region of provenance of seeds and seedlings was the same (Extremadurense region). For $Q$. suber, the provenance of seeds was different (Sierra Morena Oriental) than of seedlings (Sierra Morena Occidental), although the two regions are very proximate and had a similar climate. Moreover, Hamrick (2004) suggests that woody species have more than $90 \%$ of their total genetic diversity within populations rather than among them. In summary, we do not think it may be an important source of error.

In short, $Q$. ilex and $Q$. suber establishment should be considered either by seeding or planting showing each method's advantages and disadvantages (Appendix S4). For both alternatives, seeding offers the most promise in terms of cost-effectiveness (about 845 euros ha ${ }^{-1}$, see Appendix S5), but this method presents some disadvantages. For example, the seeding method can fail due to the effect of acorn predation by wild and domestic animals (Smit et al. 2009) or may be difficult to execute when seed is in short supply (Quercus may have infrequent mast years, and they show recalcitrant seeds that cannot be stored for long periods). Planting 1-year-old seedlings showed the highest survival percentages, but this is more expensive than direct seeding (about 1,200 euros ha ${ }^{-1}$, see Appendix S5). Both methods would need to control the weeds with an approximate cost of 150 euros per year. Planting 3-year-old seedlings showed medium to low survival percentages and is the most expensive method (about 2,000 euros ha ${ }^{-1}$, see Appendix S5). However, this method offers the advantage of shortening the initial growth period, which appears to be an important threshold affecting the economic attractiveness of plantations for $Q$. ilex and $Q$. suber planting in southern Spain (or in Mediterranean areas). Shortening the period of establishment is a useful silvicultural strategy in areas where intense pressure from browsing animals exerts a strong influence on vegetation. In areas where wild or domestic animals exclosures are needed to permit the development of regeneration, the duration of effective exclusion seldom exceeds 3-5 years. Therefore, the use of 2-3-year-old seedlings of Quercus spp. could be a positive alternative. Moreover, although larger seedlings are more expensive to plant than smaller ones, the former can be planted at lower densities in order to reduce costs (Dey et al. 2008). Previous studies (Rey Benayas and Camacho-Cruz 2004) have indicated a positive growth response of this stock type where cultural treatments are possible. However, a complex number of physiological mechanisms may underlie differences in seedling response related to size and root development (Tsakaldimi et al. 2009; Pemán et al. 2006). Specifically, leaf water conditions and soil-root interaction probably differed in that large seedling plants resulted in more water stress and lower fine root functionality, which leads to the loss of initial response of growth and survival (Wilson et al. 2007) during the 
first several months of the growing season. By contrast, small seedlings from nursery and from seeds have been associated with a better morphological condition and more efficient physiological status (Tsakaldimi et al. 2009).

\section{Conclusions}

Two different artificial regeneration methods (viz. direct seeding and planting) and two seedling ages (1-year-old seedlings and 3-year-old seedlings) were found to result in differential plant survival percentages. Each method, however, has some advantages. Thus, seeding was the least expensive method, with the roots growing in depth, but having medium survival percentages. Planting 1-year-old seedlings showed the highest survival percentages but was more expensive than seeding. Planting 3-year-old seedlings showed medium to low survival percentages depending on pot size and is the most expensive method, but it shortens the vegetative period in the field. Success percentages for directseeded plants can be raised by using large acorns. Regarding plant size, although 3-year-old seedlings of $Q$. ilex exhibited decreased survival percentages, this method has the potential advantage of shortening the plant juvenile period. However, it requires using large containers, which increases costs. Large seedlings grown in small containers undergo root deformation and are exposed to increased water stress, which diminish stomatal conductance and RGR rates.

Acknowledgements This study was supported by grant FPI-MEC, awarded to V.G-R (BES-2006-13059), and by the coordinated Spanish MEC Project DINAMED (CGL2005-05830-C03-02/BOS), INTERBOS (CGL2008-04503-CO3-02) and FEDER funds. We thank "Viveros San Jerónimo" (Consejeria de Medio Ambiente de Andalucía, Spain) for providing the studied plants. Thanks to Dr. A. del Campo, one anonymous referees and Dr. Jacobs, who made useful comments on a previous version of the manuscript. We also wish to thank José Manuel Quero, Pedro Lara, Fernando Puig and Bartolomé Arévalo for facilitating the seed collection in the Parque Natural Sierra de Cardeña and Montoro (Córdoba, Spain). Our research group is a member of the GLOBIMED network on forest ecology.

\section{References}

Ashton PMS, Yoon K, Thadani R, Berlyn GP (1999) Seedlings leaf structure of New England maples (Acer) in relation to light environment. For Sci 45:1-8

Brasier CM (1996) Phytophthora cinnamomi and oak decline in southern Europe. Environmental constraints including climate change. Ann For Sci 53:347-358

Cavender-Bares J, Bazzaz FA (2000) Changes in drought response strategies with ontogeny in Quercus rubra: implication for scaling from seedlings to mature trees. Oecologia 124:8-18

Chirino E, Vilagrosa A, Hernández EI, Matos A, Vallejo VR (2008) Effects of a deep container on morpho-functional characteristics and root colonization in Quercus suber L. seedlings for reforestation in Mediterranean climate. For Ecol Manag 256:779-785
Cochard H, Breda N, Granier A (1996) Whole tree hydraulic conductance and water loss regulation in Quercus during drought: evidence for stomatal control of embolism? Ann For Sci 53:197-206

Cornelissen JHC, Castro Diez P, Hunt R (1996) Seedling growth, allocation and leaf attributes in a wide range of woody plant species and types. J Ecol 84:755-765

Cuesta B, Villar-Salvador P, Puértolas J, Jacobs DF, Rey Benayas JM (2010) Why do large, nitrogen rich seedlings better resist stressful transplanting conditions? A physiological analysis in two functionally contrasting Mediterranean forest species. For Ecol Manag 260:71-78

Davis AS, Jacobs DF (2005) Quantifying root system quality of nursery seedlings and relationship to outplanting performance. New For 30:295-311

Del Campo AD, Navarro-Cerrillo RM, Ceacero CJ (2010) Seedling quality and field performance of commercial stocklots of containerized Holm oak (Quercus ilex) in Mediterranean Spain: an approach for establishing a quality standard. New For 39:1937

Dey DC, Jacobs D, McNabb K, Miller G, Baldwin V, Foster G (2008) Artificial regeneration of major oak (Quercus) species in the eastern United States. A review of the literature. For Sci 54:77106

Eissenstat DM (1992) Costs and benefits of constructing roots of small diameter. J Plant Nutr 15:763-782

Grossnickle SC (1988) Planting stress in newly planted jack pine and white spruce. I. Factors influencing water uptake. Tree Physiol 4:71-83

Hamrick JL (2004) Response of forest trees to global environmental changes. For Ecol Manage 197:323-335

Hoffmann WA, Poorter H (2002) Avoiding bias in calculations of relative growth rate. Ann Bot Lond 80:37-42

Jacobs DF, Salifu KF, Seifert JR (2005) Relative contribution of initial root and shoot morphology in predicting field performance of hardwood seedlings. New for 30:235-251

Jacobs DF, Salifu KF, Davis AS (2009) Drought susceptibility and recovery of transplanted Quercus rubra seedlings in relation to root system morphology. Ann Sci 66:504-512

Jiménez MP, Díaz PM, Iglesias S, De Tuero M, Gil L (1996) Las regiones de procedencia de Q. ilex en España. Icona, Madrid, p 93

Johnson PS, Shifley SR, Rogers R (2002) The ecology and silviculture of oaks. CABI Publishing, New York, $503 \mathrm{pp}$

Kaplan EL, Meier P (1958) Nonparametric estimation for incomplete observations. J Am Stat Assoc 53:457-481

King SL, Keeland BD (1999) Evaluation of reforestation in the lower Mississippi river alluvial valley. Restor Ecol 7:348-359

Lloret F, Casanova C, Peñuelas J (1999) Seedling survival of Mediterranean shrubland species in relation to root:shoot ratio, seed size and water and nitrogen use. Funct Ecol 13:210-216

Luis VC, Puértolas J, Climent J, Peters J, Gónzalez-Rodríguez AM, Morales D, Jiménez MS (2009) Nursery fertilization enhances survival and physiological status in Canary Island pine (Pinus canariensis) seedlings planted in a semiarid environment. Eur J Forest Res 128:221-229

Madsen P, Löf M (2005) Reforestation in southern Scandinavia using direct seeding of oak (Quercus robur L.). Forestry 78:55-64

Martín-Albertos S, Díaz-Fernández PM, De Miguel J (1998) Regiones de procedencia de especies forestales españolas. Descripción y principales características. Géneros Abies, Fagus, Pinus y Quercus. Organismo Autónomo de Parques Nacionales, Madrid. $23 \mathrm{p}$

Mediavilla S, Escudero A (2004) Stomatal responses to drought of mature trees and seedlings of two co-occurring Mediterranean oaks. For Ecol Manag 187:281-294 
Mendoza I, Zamora R, Castro J (2009) A seeding experiment for testing tree-community recruitment under variable environments: implications for forest regeneration and conservation in Mediterranean habitats. Biol Conserv 142:1491-1499

Navarro-Cerrillo RM, Villar P, Del Campo A (2007) Morfologia y establecimiento de los plantones. In: Cortina J, Peñuelas JL, Puértolas J, Savé R, Vilagrosa A (eds) Calidad de planta forestal para la restauración en ambientes mediterráneos. Ministerio de Medio ambiente, Madrid, pp 67-88

Navarro FB, Jiménez MN, Ripoll MA, Fernández-Ondoño E, Gallego E, De Simón E (2006) Direct sowing of holm oak acorns: effects of acorn size and soil treatment. Ann For Sci 63:961-967

Oliet JA, Planelles R, Artero F, Valverde R, Jacobs DF, Segura ML (2009) Field performance of Pinus halepensis planted in Mediterranean arid conditions: relative influence of seedling morphology and mineral nutrition. New For 37:313-331

Padilla FM, Pugnaire FI (2007) Rooting depth and soil moisture control Mediterranean woody seedling survival during drought. Funct Ecol 21:489-495

Palacios G, Navarro-Cerrillo RM, Del Campo A, Toral M (2009) Site preparation, stock quality and planting date effect on early establishment of Holm oak (Quercus ilex L.) seedlings. Ecol Eng $35: 38-46$

Pemán J, Voltas J, Gil-Pelegrín E (2006) Morphological and functional variability in the root system of Quercus ilex L. subject to confinement: consequences for afforestation. Ann For Sci 63:425-430

Poorter H, Garnier E (1999) Ecological significance of inherent variation in relative growth rate and its components. In: Pugnaire FI, Valladares F (eds) Handbook of functional plant ecology. Marcel Dekker, New York, pp 81-120

Poorter H, Niinemets U, Poorter L, Wright IJ, Villar R (2009) Causes and consequences of variation in leaf mass per area (LMA): a meta-analysis. New Phytol 182:565-588

Puértolas J, Gil L, Pardos JA (2003) Effects of nutritional status and seedling size on field performance of Pinus halepensis planted on former arable land in the Mediterranean basin. Forestry 76:159168

Quero JL, Villar R, Marañón T, Zamora R, Poorter L (2007) Seedmass effects in four Mediterranean Quercus species (Fagaceae) growing in contrasting light environments. Am J Bot 94:17951803

Rey Benayas JM, Camacho-Cruz A (2004) Performance of Quercus ilex saplings planted in abandoned Mediterranean cropland after long-term interruption of their management. For Ecol Manage 194:223-233
Ruiz-Robleto J, Villar R (2005) Relative growth rate and biomass allocation in ten woody species with different leaf longevity using phylogenetic independent contrasts (PICs). Plant Biol 7:484-494

Smit C, Díaz M, Jansen P (2009) Establishment limitation of holm oal (Quercus ilex subsp. ballota (Desf.) Samp.) in a Mediterranean savanna-forest ecosystem. Ann For Sci 66:511-517

Stanturf JA, Kennedy HE (1996) Survival and growth of planted and direct-seeded Cherrybark oak in South Carolina. South J Appl Forest 20:194-196

Stanturf JA, Schweitzer CJ, Gardiner E (1998) Afforestation of marginal agricultural land in the lower Mississippi River Alluvial Valley, USA. Silva Fenn 32:281-297

Stanturf JA, Conner WH, Gardiner ES, Schweitzer CJ, Ezell AW (2004) Recognizing and overcoming difficult site conditions for afforestation of bottomland hardwoods. Ecol Res 22:183-193

Stewart JD, Bernier PY (1995) Gas exchange and water relations of 3 sizes of containerized Picea mariana seedlings subjected to atmospheric and edaphic water stress under controlled conditions. Ann Sci For 52:1-9

Tsakaldimi M, Tsitsoni T, Ganatsas P, Zagas T (2009) A comparison of root architecture and shoot morphology between naturally regenerated and container-grown seedlings of Quercus ilex. Plant Soil 324:103-113

Vilagrosa A, Bellot J, Vallejo VR, Gil-Pelegrín E (2003) Cavitation, stomatal conductance, and leaf dieback in seedlings of two cooccurring Mediterranean shrubs during and intense drought. J Exp Bot 54:2015-2024

Villar-Salvador P (2003) La calidad de la planta en los proyectos de revegetación. In: Rey Benayas JM, Espigares T, Nicolau JM (eds) Restauración de ecosistemas mediterráneos. Universidad de Alcalá, Madrid, pp 65-86

Villar-Salvador P, Planelles R, Enríquez E, Peñuelas Rubira J (2004) Nursery cultivation regimes, plant functional attributes, and field performance relationships in the Mediterranean oak Quercus ilex L. For Ecol Manag 196:257-266

Villar-Salvador P, Valladares F, Domínguez-Lerena S, Ruiz-Díez B, Fernández-Pascual M, Delgado A, Peñuelas Rubira JL (2008) Functional traits related to seedling transplanting performance in the Mediterranean leguminous shrub Retama sphaerocarpa: insights from a provenance, fertilization and rhizobial inoculation study. Environ Exp Bot 64:145-154

Wilson ER, Vitols KC, Park A (2007) Root characteristics and growth potential of container and bare-root seedlings of red oak (Quercus rubra L.) in Ontario, Canada. New For 34:163-176

Zaczek JJ, Steiner KC, Bowersox TW (1996) Northern red oak planting stock: 6-year results. New For 13:175-189 